\title{
Social demand for oral surgery in third age patients and its association with systemic pathologies
}

\author{
José-María Martínez-González ${ }^{1}$, Félix Martín-López ${ }^{2}$, Cristina Barona-Dorado ${ }^{3}$, Natalia Martínez-Rodrí- \\ guez $^{4}$, Jose-Luis Calvo-Guirado ${ }^{5}$
}

${ }^{1}$ Full Professor of Maxillofacial Surgery in the School of Dentistry, Complutense University of Madrid. Head of the Department of Oral Facial and Implant Surgery, University Hospital of Madrid

${ }^{2}$ Oral Surgeon. University Hospital Gregorio Marañón

${ }^{3}$ Assistant Director of the Master's in Oral and Dental Implant Surgery program, University Hospital of Madrid

${ }^{4}$ Oral Surgeon, University Hospital of Madrid

${ }^{5}$ Full Professor at the Integrated Clinic for Adults. School of Dentistry, University of Murcia

Correspondence:

School of Dentistry

Pza Ramón y Cajal s/n

Madrid, Spain

hospimar@hotmail.com

Received: 13/04/2009

Accepted: 22/07/2010

\begin{abstract}
Martínez-González JM, Martín-López F, Barona-Dorado C, MartínezRodríguez N, Calvo-Guirado JL. Social demand for oral surgery in third age patients and its association with systemic pathologies. Med Oral Patol Oral Cir Bucal. 2010 Nov 1;15 (6):e875-9.

http://www.medicinaoral.com/medoralfree01/v15i6/medoralv15i6p875.pdf
\end{abstract}

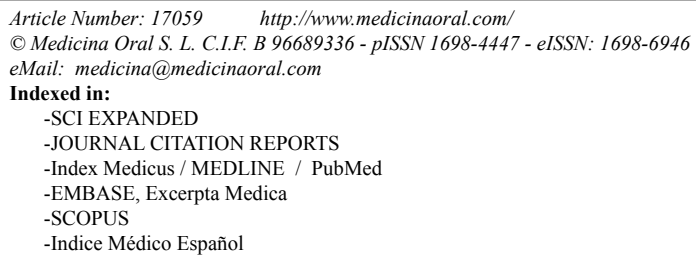

-Indice Médico Españo

\begin{abstract}
Objectives: To determine the frequency of systemic pathologies in patients aged 65 years or more, who require oral care and possibly oral surgery.

Study Design: We carried out a cross-sectional descriptive study reviewing 3,388 medical histories for patients from the Department of Medicine and Oral Surgery of the School of Dentistry at the Complutense University of Madrid, who had requested surgical treatment. Those selected were at least 65 years of age or more, and were grouped according to their medical histories into categories of pathologies, which include: systemic, cardiovascular, digestive, respiratory, endocrine-metabolic, genitourinary, osteoarticular, nervous system and the sensory organs.

Results: Patients over the age of 65 most commonly present cardiovascular and digestive pathologies, which represent values of $30.8 \%$ and $13.75 \%$, respectively. The rest of the systemic pathologies analyzed were categorized according to frequency, as follows: endocrino-metabolic pathologies $6.66 \%$, respiratory pathologies $6.25 \%$, genitourinary pathologies $3.75 \%$, osteoarticular pathologies $2.91 \%$, and pathologies of the nervous system and sensory organs $2.08 \%$.

Conclusions: The demand for surgical treatments by third age patients was relatively low, representing $2.18 \%$. However, the presence of systemic pathologies was constant, and therefore, the anamnesis and patient medical history are fundamental for any surgical treatment.
\end{abstract}

Key words: Third age, systemic pathology, oral surgery. 


\section{Introduction}

Throughout the last century, we have witnessed an aging of the population in developed societies due to the many health, safety, labor, social and economic advances. It is evident that this trend still continues despite the migration flows that our society is experiences, such that in our neighboring countries, those aged 65 years and over represent $14-15 \%$ of the total population, with this figure expected to reach $27.9 \%$ in Europe in 2050 (1).

The senior citizen population, which consists of those aged 65 years and over (historically accepted chronological criteria and based on which the body's overall efficiency and tolerance to external influences is limited for the majority of those in this age group), accounts for $17 \%$ of the total population in Spain, that is, $7,276,000$ people.

In addition, an aging of an already elderly population is taking place. Whereas in 1986 the number of those aged 80 years or more was 916,489 , this figure increased to $1,756,844$ octogenarians in Spain in 2003, representing $4.1 \%$ of the total population. In 2050 , this percentage will have increased to $11.4 \%$, accounting for more than $6,000,000$ people.

Presumably, these gains, which are accompanied by an improvement in the quality of life, will also mean an increase in the development of pathologies in the oral cavity requiring surgical treatment, not only due to the pathologies themselves, but for rehabilitation purposes. In any case, the presence of systemic pathologies or drug treatment must be taken into serious consideration.

In this regard, the scientific literature offers few studies on the demand for care by this population group, and therefore, the objective of this study was to determine the frequency of systemic pathologies in patients aged 65 and over who require oral health care with the possibility of surgical treatment.

\section{Patients and Methods}

We performed a cross-sectional descriptive study reviewing 3,388 medical records of patients from the Department of Oral Medicine and Surgery of the School of Dentistry at Complutense University of Madrid, who had requested surgical treatment, selecting those who were aged at least 65 years or more.

We established two age groups, according to the criteria proposed by Katz et al. (2) and Holm-Pedersen et al. (3): "Independent seniors", which represent the majority of people over the age of 65 who live in their own home, often with their spouse and are relatively healthy people. They often have a mild yet controlled clinical disorder (arthritis, hypertension, etc.) and account for $70-80 \%$ of the senior population. "Frail elderly persons" are members of this population of people aged 80 and older and are especially vulnerable. The following criteria is usually used to determine frailty: presence of two or more chronic diseases, recent hospitalization, polypharmacy ( 5 or more drugs), aged over 80 years, living alone and low financial income.

In all cases, the medical records were grouped into the following categories of pathologies: systemic, cardiovascular, digestive, respiratory, endocrino-metabolic, genitourinary, osteoarticular, nervous system and sensory organs.

\section{Results}

The number of patients aged 65 years and over and requiring oral surgery was 74 individuals, representing $2.18 \%$ of the sample studied. Of these, 67 belong to the "independent seniors" group, with ages ranging between 65 and 80 years, and 7 (9.45\%) belong to the "frail elderly" population, which consists of those aged 80 years or more. The sex distribution was 39 males for every 35 females, with a ratio of males versus females equal to 1: 0.8 . The age ranged between 65 and 87 years, with an average age of 70.31 years.

The results obtained from the patient medical history helped to determine that the presence of cardiovascular and digestive pathologies were most common, with the former affecting $30.8 \%$ of the patients and the latter affecting $13.75 \%$ (Table 1). The rest of the systemic pathologies corresponded to the following pattern: endocrino-metabolic $6.66 \%$, respiratory $6.25 \%$, genitourinary $3.75 \%$, osteoarticular $2.91 \%$, and nervous system and sensory organs $2.08 \%$ (Table 2 ).

Among the cardiovascular pathologies, the most frequent was hypertension, affecting $22.97 \%$ of all patients and representing $40.5 \%$ of all the pathologies of this type, occurring more frequently in women.

The presence of heart failure was also observed in $11.91 \%$ of the patients, followed by a history of peripheral vascular disease, auricular fibrillation and acute myocardial infarction, these five pathologies representing over $75 \%$ of the histories of cardiovascular diseases.

As for digestive pathologies, chronic gastritis and gastric ulcers were among those most common, representing $45.45 \%$, with similar percentages in both cases. These two pathologies, along with the cases of irritable bowel syndrome and hiatal hernia, accounted for $72.75 \%$ among the four pathologies.

Within the group of endocrino-metabolic pathologies, diabetes mellitus was the most frequent, representing $62.51 \%$ and affecting men and women in equal percentages. Among the patients, $50.01 \%$ were treated with oral anti-diabetics (Diabetes mellitus type II); while 12.50\% were insulin dependent. Pathologies affecting the thyroid gland were the second most common, with disorders including hypothyroidism and goiters.

In relation to respiratory diseases, we found that $10.81 \%$ of the patients had chronic obstructive pulmonary disease (COPD), representing $53.30 \%$ of the respiratory 
Table 1. Distribution in percentages of the cardiovascular and digestive pathologies collected while obtaining the patient's medical history.

\begin{tabular}{|c|c|c|}
\hline \multicolumn{3}{|c|}{ CARDIOVASCULAR PATHOLOGIES } \\
\hline VALUE & FREQUENCY & $\%$ \\
\hline High blood pressure & 17 & 40.47 \\
\hline Heart failure & 5 & 11.91 \\
\hline $\begin{array}{l}\text { Peripheral vascular dis- } \\
\text { ease }\end{array}$ & 4 & 9.52 \\
\hline Auricular fibrillation & 3 & 7.15 \\
\hline $\begin{array}{l}\text { Acute myocardial infarc- } \\
\text { tion }\end{array}$ & 3 & 7.15 \\
\hline $\begin{array}{l}\text { Hypertrophic cardiomyo- } \\
\text { pathy }\end{array}$ & 2 & 4.76 \\
\hline Mitral insufficiency & 2 & 4.76 \\
\hline Intermittent claudication & 2 & 4.76 \\
\hline Aortic stenosis & 1 & 2.38 \\
\hline Mitral prosthesis & 1 & 2.38 \\
\hline Pacemakers & 1 & 2.38 \\
\hline Ischemic cardiopathy & 1 & 2.38 \\
\hline TOTAL & 42 & 100 \\
\hline \multicolumn{3}{|c|}{ DIGESTIVE PATHOLOGIES } \\
\hline VALUE & FREQUENCY & $\%$ \\
\hline Chronic gastritis & 8 & 24.24 \\
\hline Gastric ulcer & 7 & 21.21 \\
\hline Irritable bowel syndrome & 5 & 15.20 \\
\hline Hiatal hernia & 4 & 12.10 \\
\hline Duodenal ulcer & 2 & 6.20 \\
\hline Chronic hepatitis & 2 & 6.20 \\
\hline Cholecystechtomy & 2 & 6.06 \\
\hline Crohn's Disease & 1 & 3.03 \\
\hline Inguinal hernia & 1 & 3.03 \\
\hline Cirrhosis & 1 & 3.03 \\
\hline TOTAL & 33 & 100 \\
\hline
\end{tabular}

Table 2. Distribution in percentages of the following pathologies: endocrino-metabolic, respiratory, genitourinary, osteoarticular, nervous system and sensory organs.

\begin{tabular}{|c|c|c|}
\hline \multicolumn{3}{|c|}{ ENDOCRINO-METABOLIC PATHOLOGIES } \\
\hline VALUE & FREQUENCY & $\%$ \\
\hline Type II Diabetes Mellitus & 8 & 50.01 \\
\hline Type I Diabetes Mellitus & 2 & 12.50 \\
\hline Hypothyroidism & 2 & 12.50 \\
\hline Goiter & 1 & 6.30 \\
\hline Hypercholesterolemia & 1 & 6.30 \\
\hline Hyperuricemia & 1 & 6.30 \\
\hline Obesity & 1 & 6.30 \\
\hline TOTAL & 16 & 100 \\
\hline \multicolumn{3}{|c|}{ RESPIRATORY PATHOLOGIES } \\
\hline VALUE & FREQUENCY & $\%$ \\
\hline $\begin{array}{l}\text { Chronic obstructive pulmonary } \\
\text { disease COPD }\end{array}$ & 8 & 53.30 \\
\hline Asthma & 3 & 20.00 \\
\hline Sinusitis & 2 & 13.30 \\
\hline Silicosis & 1 & 6.70 \\
\hline Tuberculosis & 1 & 6.70 \\
\hline TOTAL & 15 & 100 \\
\hline \multicolumn{3}{|c|}{ GENITOURINARY PATHOLOGIES } \\
\hline VALUE & FREQUENCY & $\%$ \\
\hline Renal lithasis (kidney stones) & 3 & 33.30 \\
\hline Prostatic hypertrophy & 2 & 22.20 \\
\hline Prostatectomy & 2 & 22.20 \\
\hline Recurrent cystitis & 1 & 11.10 \\
\hline Ovarian cyst & 1 & 11.10 \\
\hline TOTAL & 9 & 100 \\
\hline \multicolumn{3}{|c|}{ OSTEOARTICULAR PATHOLOGIES } \\
\hline VALUE & FREQUENCY & $\%$ \\
\hline Arthrosis & 4 & 57.20 \\
\hline Osteoporosis & 2 & 28.60 \\
\hline Gonarthrosis & 1 & 14.30 \\
\hline TOTAL & 7 & 100 \\
\hline \multicolumn{3}{|c|}{$\begin{array}{c}\text { PATHOLOGIES OF THE NERVOUS SYSTEM } \\
\text { AND SENSORY ORGANS }\end{array}$} \\
\hline VALUE & FREQUENCY & $\%$ \\
\hline Parkinson's Disease & 2 & 40.00 \\
\hline $\begin{array}{l}\text { Cerebravascular attack ACVA } \\
\text { (stroke) }\end{array}$ & 1 & 20.00 \\
\hline Trigeminal Neuralgia & 1 & 20.00 \\
\hline Deafness in the right ear & 1 & 20.00 \\
\hline TOTAL & 5 & 100 \\
\hline
\end{tabular}




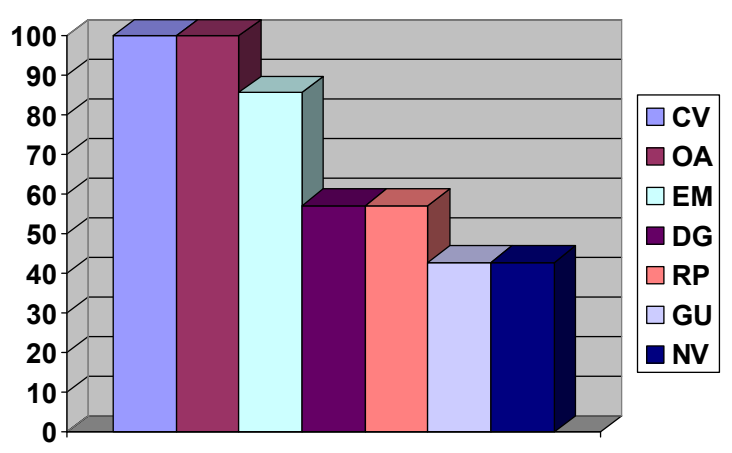

Fig. 1. Distribution of the frequency of diseases in frail elderly patients over 80 years of age. CV: cardiovascular OA: osteoarticular EM: endocrino-metabolic diseases DG: digestive RP: respiratory GU: genitounirary NV: nervous system and sensory organs.

disorders and it being more common in men than in women, 1: 0.6 .

COPD, along with a history of asthma, accounted for $73.30 \%$ of the respiratory cases.

As for genitourinary pathologies, these were found to be more common among men, by a ratio of 1 : 0.6 compared to women. Kidney stones, prostatic hypertrophy and prostate surgery represented a value of $77.7 \%$.

With regard to osteoarticular pathologies, the frequency was higher for the presence of osteoarthritis and osteoporosis, which accounted for $57.20 \%$ and $28.60 \%$, respectively.

As for pathologies of the nervous system, Parkinson's disease was the most frequent, although the percentage of patients affected by these pathologies was the lowest, occurring in two patients, which represents $40 \%$ of this group of pathologies.

In assessing the frail elderly group, this study has only been able to collect observations for 7 patients, who presented different pathologies at the time of the interview. Even though it was a very low percentage, the distribution according to pathology groups was: cardiovascular and osteoarticular $100 \%$, endocrino-metabolic $85.71 \%$, digestive and respiratory $57.14 \%$ and genitourinary and nervous system $42.85 \%$ (Fig. 1).

\section{Discussion}

In this study, we selected a population group aged over 65 years, considering this group to be patients who usually have some underlying pathology and may be subjected to drug therapy. Any surgery can have an impact on the illness itself, or the illness can even alter the treatment or the postoperative progress.

The percentage of patients analyzed was small, only $2.18 \%$ of the 3388 patients, which could raise the question of whether this group has little demand for oral surgical treatment. We understand that sometimes these values may not reflect the actual demand, given that the demographics of the area of health with which each patient is associated might be different from one to another.

The average age of our patients was 70.31 years. The fact that so few patients over the age of 80 years were treated may be due to the situation discussed above or even due to their physical conditions not being the most appropriate, and therefore, they are not in a position to be treated as outpatients.

However, we understand that the both dentists as well as the stomatologists will treat third age patients increasingly more often, and for these patients, the attention should be especially careful, depending on the systemic pathologies from which these patients suffer and the drug treatments they follow $(4,5)$. In addition, oral health care should be planned based on patient's health status, taking into account that the frail elderly population will suffer conditions which limit them physically, mentally or socially.

The physiological changes associated with senescence, contribute to a greater prevalence of chronic diseases, as demonstrated in this study, in which all the patients studied had underlying pathologies and thus were undergoing prescription drug treatments.

Due to the prevalence of cardiovascular pathologies $(30.8 \%)$ and digestive pathologies (13.75\%) observed in this study, more precautions should be taken -especially in the case of the former- for oral surgery.

In cardiovascular diseases, the incidence of heart failure and pulmonary edema increases exponentially with age after the sixth decade, in relationship to the presence of hypertension and / or previous myocardial infarction. Patients who have heart failure may also present hypertension and the risk of hemorrhaging, hypotension due to heart failure, heart rhythm disturbances with dizziness, fainting and acute pulmonary edema, which are all situations that can complicate surgery. Furthermore, ischemic heart disease, heart failure and heart rhythm disturbances can be altered with anemia, which is frequently associated with chronic conditions (6-8).

The presence of an endocrino-metabolic pathology occupied the third place, representing $6.66 \%$, highlighting diabetes mellitus.

Regardless of the demonstrated association between diabetes and periodontal disease, which can lead to tooth loss in these patients, surgical treatment may influence the underlying pathology, with anxiety and surgical stress having an effect on the metabolism of carbohydrates, and even causing shock or hypertension in patients with adrenal insufficiency. In addition, the postoperative drug therapies must be taken into account, particularly in diabetic patients, mainly with NSAIDs (9-11). 
Respiratory disease can impose certain postural difficulties in the case of long surgical treatments. Similarly, it should be noted that chronic hypoxemia in these patients will lead to a compensatory polycythemia, which may even depress the megakaryocytic and myeloid series in bone marrow, producing neutropenia and thus an increased risk of infection. The same situation may contribute to the appearance of thrombocytopenia, which along with hepatic dysfunction due to ecstasy and / or hypoxia, would lead to the risk of hemorrhage due to decreased activity of the prothrombin (12-14).

Osteoarticular pathology is also worth mentioning, which only affected $2.91 \%$ of the patients in this study. It is likely that these percentages may have a certain bias and that some of the patients interviewed did not elaborate on their status due to not having any symptoms.

We believe that taking into account the vulnerability that has been created with the use of bisphosphonates for patients with osteoporosis, it is now more than justified to obtain a comprehensive medical history from these patients. Although the literature shows very low values for bisphosphonates that are administered orally, it is advisable to have better control of the surgical treatments and to consider the course of action to take in the event osteonecrosis should appear (15-17).

Based on all these observations, it appears that the medical history, a vital tool in daily practice, will prove to be the health professional's biggest ally when treating elderly patients, given that with a proper medical history, we will know what underlying pathologies the patient has before surgery, and this will provide us guidance regarding the patient's ability to tolerate the treatment. In this sense, it is important to note that sometimes it is difficult to collect information from elderly patients, as some patients suffer mental deterioration. Therefore, it will be important to count on the assistance of a third party (relative or institutions) to help us in this effort. In addition, the health professional must understand the needs and priorities of each patient and his or her expectations regarding the success of the treatment.

If the patient's medical history is partially compromised, it is clear that a clinical examination may give us more information about the patient and thus we should perform a prior physical examination, which includes listening to the heartbeat and lungs, taking the blood pressure, pulse, and observation of the jugular veins and ankle edema supported by an analytical study (CBC, coagulation and biochemistry). In the case of positive findings, the practitioner should decide whether the patient will tolerate the surgical process or will require the assistance of a specialist in order to stabilize the patient. Previous considerations regarding the adjustment of the patients' dose for usual medications, diet modification, stress reduction, adequate local anesthesia and the pre- vention of bacteremia and infection, are also factors to take into account if we want to avoid complications.

Similarly, oral surgical treatments will be performed by taking into account the comorbidity of the elderly person, and one should make the choice to proceed with surgical treatment after having assessed the riskbenefit ratio. In the cases where surgery is likely to be involved, surgery complications may occur in relation to the chronic polypharmacy that elderly patients often need, the drugs administered during anesthesia and the underlying illnesses that the patients present.

\section{References}

1. Ettinger RL. Demography and dental needs, an international perspective. Gerodontology. 1993;10:3-9.

2. Katz S, Ford AB, Moskowitz RW, Jackson BA, Jaffe MW. Studies of illness in the aged. The index of ADL: a standardized measure of biological and psychosocial Function. JAMA. 1963;185:914-9.

3. Holm-Pedersen P, Loe H. Geriatric Dentistry. Ed. Copenhague Munksgaard; 1986

4. Silvestre FJ, Miralles L, Llambes F, Bautista D, Solá-Izquierdo E, Hernández-Mijares A. Type 1 diabetes mellitus and periodontal disease: relationship to different clinical variables. Med Oral Patol Oral Cir Bucal. 2009;14:E175-9.

5. Terezhalmy GT. Rational pharmacotherapy for the elderly. Dent Clin North Am. 1989;33:59-66.

6. Nolan L, O’Malley K. Prescribing for the elderly. Part I: Sensitivity of the elderly to adverse drug reactions. J Am Geriatr Soc. 1988;36:142-9.

7. Feely J, Coakley D. Altered pharmacodynamics in the elderly. Clin Geriatr Med. 1990;6:269-83.

8. Margaix Muñoz M, Jiménez Soriano Y, Poveda Roda R, Sarrión G. Cardiovascular diseases in dental practice. Practical considerations. Med Oral Patol Oral Cir Bucal. 2008;13:E296-302.

9. Greenblatt DJ. Reduced serum albumin concentration in the elderly: a report from the Boston Collaborative Drug Surveillance Program. J Am Geriatr Soc. 1979;27:20-2.

10. Gómez-Moreno G, Guardia J, Cutando A, Calvo-Guirado JL. Pharmacological interactions of anti-inflammatory-analgesics in odontology. Med Oral Patol Oral Cir Bucal. 2009;14:E81-9.

11. Jover Cerveró A, Bagán JV, Jiménez Soriano Y, Poveda Roda R. Dental management in renal failure: patients on dialysis. Med Oral Patol Oral Cir Bucal. 2008;13:E419-26.

12. De Jong KJ, Oosting J, Peters GJ, Abraham-Inpijn L. Detecting medical problems in dentistry: a survey of 4,087 patients in The Netherlands. Eur J Med. 1992;1:23-9.

13. Lockhart PB, Gibson J, Pond SH, Leitch J. Dental management considerations for the patient with an acquired coagulopathy. Part 1: Coagulopathies from systemic disease. Br Dent J. 2003;195:439-45.

14. Mainous EG, Boyne J. Hepatic coma after multiple dental extractions: report of case. J Oral Surg. 1974;32:682-4.

15. Pérez SB, Barrero MV, Hernández MS, Knezevic M, Navarro JM, Millares JR. Bisphosphonate-associated osteonecrosis of the jaw. A proposal for conservative treatment. Med Oral Patol Oral Cir Bucal. 2008;13:E770-3.

16. Gómez Font R, Martínez García ML, Olmos Martínez JM. Osteochemonecrosis of the jaws due to bisphosphonate treatments. Update. Med Oral Patol Oral Cir Bucal. 2008;13:E318-24.

17. Infante Cossío P, Cabezas Macián A, Pérez Ceballos JL, Palomino Nicas J, Gutiérrez Pérez JL. Bisphosphonate-related osteonecrosis of the jaw in patients with multiple myeloma. Med Oral Patol Oral Cir Bucal. 2008;13:E52-7. 